\title{
Effect of Sediment Suspensions on Seawater Salinity Assessments
}

\author{
Marc Le Menn*, Laurent Pacaud \\ Metrology and Chemical Oceanography Department, French Hydrographic and Oceanographic Service (Shom), Brest, France
}

\section{Email address:}

Marc.lemenn@shom.fr (M. L. Menn), Laurent.pacaud@shom.fr (L. Pacaud)

*Corresponding author

\section{To cite this article:}

Marc Le Menn, Laurent Pacaud. Effect of Sediment Suspensions on Seawater Salinity Assessments. Journal of Water Resources and Ocean Science. Vol. 6, No. 2, 2017, pp. 23-34. doi: 10.11648/j.wros.20170602.11

Received: January 3, 2017; Accepted: January 20, 2016; Published: April 28, 2017

\begin{abstract}
The absolute salinity of seawater can be assessed by conductivity measurements and the calculation of a practical salinity, or by density measurements. The effect of low concentrations of suspended particulate matter on these measurements has never been documented, but the theories developed to explain and predict the conductivity of sediments show clearly that, under an electrical field, they interact with the ionic composition of seawater. Moreover, it can be easily shown that adding any quantity of particles has an effect on the measured density of a seawater sample. This publication describes a measurement method settled to measure the effect of sediment particles on seawater conductivity and proposes relations for explaining and predicting the observed phenomena. It also describes the effects of particles on density measurements. The results obtained show that the errors on the measured conductivities (and practical salinities) caused by sand in suspensions, are less than 0.001 $\mathrm{mS} \mathrm{cm}$ (on average) with concentrations encountered in oceans fields, but that these cannot be neglected in some coastal areas. The amplitude of the measurement noise leaded by particles circulation in the conductivity cell exceeds 0.002 in salinity beyond $200 \mathrm{mg} \mathrm{l}^{-1}$. For density measurements, the threshold for keeping the error inferior to the uncertainty of $0.004 \mathrm{~kg} \mathrm{~m}^{-3}$ usually obtained with vibrating tube densimeters, is much lower, $9 \mathrm{mg}^{-1}$, and close to the concentrations encountered in the open ocean.
\end{abstract}

Keywords: Seawater, Salinity, Conductivity, Density, Sediment, Formation Factor, Limnology

\section{Introduction}

The international thermodynamic equations of seawater described in the TEOS-10 Manual [1] account for the variations in the composition of seawater by using the concept of absolute salinity $S_{A}$. In this manual, $S_{A}$ is defined as the mass fraction of dissolved material in seawater and is preferred to the practical salinity $S_{P}$ because it takes into account the influence of the mass of dissolved constituents, whereas $S_{P}$ takes conductivity variations into account. A material is defined as dissolved if it passes through a 0.2 $\mu \mathrm{m}$ filter [2]. $S_{A}$ is calculated by summing a reference salinity $S_{R}$ defined by Millero et al. [3] and a salinity

$$
\delta S_{A}=\left(50.7 \times \Delta\left[S_{i}\left(\mathrm{OH}_{4}\right)\right]+38.9 \times \Delta\left[\mathrm{NO}_{3}^{-}\right]+4.7 \times\left(D I C-2.080 \times S_{p} / 35\right)+55.6 \times\left(T A-2.300 \times S_{p} / 35\right)\right) / \mathrm{mmol}^{-1}
$$

According to Wright et al. [5], the standard uncertainty of the model fit is $0.08 \mathrm{mg} \mathrm{kg}^{-1}$ over the oceanic range, if all anomaly $\delta S_{A}$ described as the result of the addition of other salts such as nutrients and inorganic carbon or dissolved organic carbon:

$$
S_{A}=S_{R}+\delta S_{A}=(35.16504 / 35) S_{P}+\delta S_{A}
$$

The TEOS-10 manual suggests using the Pawlowicz et al. [4] chemical model to calculate $\delta S_{A}\left(\mathrm{mg} \mathrm{kg}^{-1}\right)$. This model is based on measurements of nitrate and silicate concentrations, and the differences between the Total Alkalinity (TA) and Dissolved Inorganic Carbon $(D I C)$ of the sample, and the best estimate of $T A$ and $D I C$ in standard seawater (expressed in $\mathrm{mol} \mathrm{kg}^{-1}$ ). That gives:

quantities are known precisely. Other studies have showed that $\delta S_{A}$ can be calculated through simplified empirical 
equations based on silicate concentrations $\left[\mathrm{S}_{i} \mathrm{O}_{2}\right]$ and alkalinity measurements because these components account best for density and salinity change in most deep waters. These empirical equations take the form:

$$
\delta S_{A}=a \Delta\left[S_{i} O_{2}\right]+b \Delta[N T A]
$$

according to Millero, [6] or Millero et al. [7], [8], [9], where $\triangle[N T A]$ is the difference between the measured value of the normalized total alkalinity NTA to a salinity of 35 and a reference value $(2300 \mu \mathrm{mol} / \mathrm{kg})$ corresponding to the $N T A$ value of the original $S_{P}$ scale for surface seawater. But the practical way used to determine $\delta S_{A}$ is based on using density measurements [10]. As described by McDougall et al. in 2012 [11] from a method suggested by Millero et al. [3], $\delta S_{A}$ can be calculated with the equation:

$$
\delta \rho=0.75179 \delta S_{A}
$$

where $\delta \rho=\rho-\rho\left(S_{R}, 25^{\circ} \mathrm{C}, 0 \mathrm{dbar}\right) . \rho$ can be measured with a vibrating tube densimeter and $\rho\left(S_{R}, 25{ }^{\circ} \mathrm{C}, 0\right.$ dbar $)$ is calculated using TEOS-10 equations from practical salinity measurements to determine $S_{R}$ with the first part of equation (1).

In these previous works, the turbidity of seawater is never taken into account. In the definition of $S_{A}$, the concept of dissolved material is defined in the case of standard seawater with a standard composition, but Pawlowicz et al. [12] recognized that 'defining dissolved inorganic solute in seawater is not entirely straightforward' and that 'the remaining of organic material is poorly understood' particularly for calculations of density and thermodynamic properties. Wright et al. [5] have clarified the concept of absolute salinity in the case of seawaters with composition anomalies and, R. Pawlowicz [13] attempted to characterize $\delta S_{A}$ in oceanic areas where seawater is diluted by river waters, but dissolved organic matter or sediments are excluded in these studies, whereas they modify seawater density and conductivity measurements, as will be shown in this publication.

The seawater turbidity comes from alluvium, clay, organic and inorganic matter, plankton and other micro-organisms. Its effects on light propagation are well known but its effects on conductivity and density measurements have been less documented. A publication of Held et al. [14] has shown a 'blinding effect' of the conductivity sensors by dissolved particles of mud. They found that measured salinity decreases with increasing salinity and particle concentrations, and according to them, for concentrations inferior to $10 \mathrm{~g} \mathrm{l}^{-1}$, the deviations are below $1.5 \%$ and are negligible for low concentrations. However, they used instruments with poor resolutions $\left(0.01\right.$ and $\left.0.1 \mathrm{mS} \mathrm{cm} \mathrm{cm}^{-1}\right)$. Thereafter, their results are useful for estuarine and some coastal waters but they cannot be used in open ocean when the accuracy required for practical salinity measurements is less than 0.01 .

It is generally admitted that suspended particulate matter (SPM) concentrations are between $0.5 \mathrm{mg} \mathrm{l}^{-1}$ and $4 \mathrm{mg} \mathrm{l}^{-1}$ in the oceans fields, $4 \mathrm{mg} \mathrm{l}^{-1}$ to $100 \mathrm{mg} \mathrm{l}^{-1}$ in some coastal waters and $100 \mathrm{mg} \mathrm{l}^{-1}$ to several $\mathrm{g} \mathrm{l}^{-1}$ in estuaries. It can be easily shown that adding any quantity of particles has an effect on the measured density of a seawater sample. The question is: when is it negligible and when is it necessary to measure turbidity, or to filter particles, to be confident in absolute salinity assessments from laboratory density measurements?

With the goal of providing initial answers to these questions, we have made measurements in the laboratory with sand, mud and kaolinite particles in order to assess their effect - at first, on conductivity measurements to a resolution of $0.001 \mathrm{mS} \mathrm{cm}^{-1}$ and, second, on density measurements with a vibrating tube densimeter. P. Held tried to study the effects of turbidity with natural mud samples. Natural mud samples present the advantages of containing organic and mineral matter and of approaching in situ measurement conditions. But, observed deviations of these measuring out are sometimes difficult to explain and it is not always easy to keep natural mud in a homogeneous suspension. This is why we chose to work with sand and kaolinite particles, which are a component of clay minerals, common components of suspended inorganic particles. The 'blinding effect' underscored by P. Held et al., is according to them, a reduction of the cross-section of conductivity cells and then it might not depend on the composition of the SPM. We also tested this assertion.

\section{Effects of Seawater on Sediment Conductivity}

Mud and suspended sediments are generally a mixture of bulk insulated particles coming from sandstone, quartz, calcite, and conductive particles from clay. Sedimentary rocks can be classified according to the size of their grains. Sandstones are composed of quartz or feldspar with average grains dimensions of $1 / 16$ to $2 \mathrm{~mm}$ but some of them can be clayed also. About $20 \%$ of sedimentary rocks are composed of carbonates like calcite, aragonite or dolomite. About 5\% are composed of evaporates like gypsum, anhydrite, and halite. $50 \%$ are composed of shales with an average diameter of less than $1 / 16 \mathrm{~mm}$. The major components of shales are illite, kaolinite, smectite and chlorite.

No theoretical model explains exactly the electrical behavior of suspended sediments. Relations describe the complex conductivity of colloidal suspensions. A colloid is the suspension of one or several substances regularly spread out in a liquid medium, forming a system with two separated phases. Colloid particles are sized from the nanometer to the micrometer and they are represented theoretically like small spheres. Kaolinite particles respond to this definition and allow the obtaining of colloidal suspensions, but kaolinite particles rarely occur alone in seawater and most of the other sediments and particularly sand grains don't form colloidal suspensions.

Moreover, empirical relations describing the average response in conductivity of sediments were discovered by 
Archie in 1942 [15]. He found that the electrical conductivity $\sigma_{0}$ of water-saturated samples of sandstone and the electrical conductivity of seawater $\sigma_{w}$ are linked by a constant called the formation factor $F F$. $F F$ is inversely proportional to the connected porosity $\phi^{n}$ where $m$, the cementation exponent, varies between 1 and 3 for set sandstones and sands [16]. For non-cohesive sands $m=1.5$ and for cohesive sands with clay $m=2$, according to other authors. According to Revil and Glover [17], $F F^{-1}$ is a measure of the effective interconnected porosity. The first Archie's law is:

$$
\sigma_{0}=F F^{-1} \sigma_{w}=\phi^{m} \sigma_{w}
$$

In the case of rocks partially saturated with water, $F F^{-1}$ or $\phi^{n}$ are multiplied by a saturation factor $S_{w}$, with a saturation exponent $n . S_{w}{ }^{n}$ describes the ratio between the volume of water and the volume of the porous space in the sample. It allows the presence of a non-conductive liquid or gas in the porous space to be taken into account. This relation can be used only for sedimentary clean rocks, i.e., without clay. But Waxman and Smits showed in 1968 [18] that this law can also be applied to clay rocks in strong salinity solutions by adding a factor describing the cationic exchange capacity (CEC). Thereafter, Archie's law can be verified for most sediments at low frequency. These relations present the advantage of taking the nature of sediments into account. They were developed for porous media but their coefficients can be adapted to suspensions.

Several theoretical models have been explored to try to explain the conductivity of clean sediments. In 1997, Revil and Glover [17] established a theory of ionic-surface electrical conduction in porous media based on the work of Johnson, Plona and Kojima [19]. They consider that, in contact with an electrolyte, mineral surfaces get an excess of charge that is balanced by mobile ions in an electrical diffuse layer (EDL), and this diffuse layer contributes to the effective electrical conductivity of the sediments. The diffuse layer and the mineral surface properties are sensitive to the fluid composition and to temperature. They describe the specific surface conductance $\Sigma_{S}$ of a saturated porous medium as being the sum of an electromigration conductance $\Sigma_{S}{ }^{e}$ in the interconnected pore space which represents the excessive ohmic conductivity in the diffuse layer (first terms in the integral of equation (6)) and of the electro-osmotic surface conductance $\Sigma_{S}{ }^{\text {s }}$ (2nd term of the integral) due to the convective electrical current in the diffuse layer:

$$
\Sigma_{S} \equiv \Sigma_{S}^{e}+\Sigma_{S}^{o s} \equiv \int_{0}^{\chi_{d}}\left[\sigma(\chi)-\sigma_{w}+\rho(\chi) \beta_{o s}(\chi)\right] d \chi
$$

Equation (6) is from P. Leroy et al. [20]. $\Sigma_{S}$ is due to an excess of ions and it represents the anomalous conduction in the thickness $\chi_{d}$ of the EDL or Debye screening length. $\chi$ is the distance from the surface of the sediment particle, $\rho$ is the volume charge density in the EDL and $\beta_{o s}$ the electro-osmotic mobility.

In 1998, Revil and Glover [16] explored a triple-layer model and defined $\Sigma_{S}$ as being the sum of three contributions: $\Sigma_{S}^{E D L}$, the ionic conduction in the EDL, $\Sigma_{S}^{S t e r n}$ the ionic conduction in the Stern layer and $\Sigma_{S}^{\text {Prot }}$ associated to proton transfer. In 2008 [21] and 2013 [20], the same model was used by P. Leroy et al. to explain the surface conductivity of packs of glass beads and of amorphous silica nanoparticles, but they replaced $\Sigma_{S}^{\text {Prot }}$ by a more general $\Sigma_{S}{ }^{0}$ representing 'the ionic conduction associated with the transfer of charges at the surface of the mineral'. As the EDL is the layer in contact with the electrolyte, $\Sigma_{S}^{E D L}$ is in relation with $\sigma_{w}$ but also with the ionic conductance in the EDL, or also with the effective mobility of charges in the fluid which depends on the electrolyte concentration or salinity, but also on the temperature and the pressure via the dynamic viscosity. This description reveals the difficulty of giving prominence to a blinding effect in conductivity cells and to assess its value even with bulk insulated sediments.

$\Sigma_{S}^{\text {Stern }}$ depends on the mobility of the adsorbed ions in the Stern layer, but also on the total surface site density of the particle able to adsorb cations, and on the relative surface density of adsorbed ions, which is dependent on the $\mathrm{pH}$ of the free electrolyte. In 2011, Revil and Skold [22] recalled that $\Sigma_{S}^{\text {Stern }}$ is dependent on temperature. They also showed that $\Sigma_{S}^{\text {Stern }}$ increases with the salinity as a consequence of the increase of ions adsorbed in the Stern layer.

The last contribution $\Sigma_{S}^{\text {Prot }}$ is, according to Revil and Glover [16], related to particles' surface conduction phenomenon such as the migration of protons or electrons. It is independent of salinity but it depends on the total site density of the mineral surface.

According to Revil and Skold [22], for sands and sandstones, $\Sigma_{S}$ is essentially proportional to $\Sigma_{S}^{E D L}$ at very low frequency, whereas, at very high frequency, it is proportional to $\Sigma_{S}^{E D L}+\Sigma_{S}^{S t e r n}$, but their contribution can vary strongly with the salinity and the $\mathrm{pH}$ of the solution as shown by $\mathrm{P}$. Leroy et al. in 2008 [21] on packs of glass beads and in 2013 on amorphous silica nanoparticles [20]. In 2008, they remarked [21] that models based on the polarization of the diffuse layer do not represent correctly granular porous medium, even though they are correct for dilute suspensions of grains with no contiguity between the grains, which corresponds to suspended particulate matter.

In 2007, A. Revil et al. [23] also modeled the electrokinetic properties of charged porous materials like clay. From Ampère's law they propounded a theory that explains Archie's law (5) and extends it to sediments containing clays. The effective electrical conductivity of these porous media can be predicted with the following equation [24]:

$$
\sigma=\frac{1}{F F}\left[S_{w}^{n} \sigma_{w}+(F F-1) \sigma_{S}\right]
$$

In this relation, $S_{w}{ }^{n}$ is the saturation factor, $n$ is the saturation exponent described previously, $\sigma_{w}$ the average seawater conductivity and $\sigma_{s}$ the average surface conductivity which translates the capacity of exchanging ions. This relation is valuable from a few hundredth $\mathrm{Hz}$ to a 
few MHz. The crystalline structure of clays generates some sites on their surface, called exchange sites, that are able to carry electrical negative loads. Under the effect of Van der Waals forces or of chemical forces (covalent bonds), this creates a phenomenon of adsorption of cations like $\mathrm{Na}^{+}, \mathrm{K}^{+}$, $\mathrm{Ca}^{+}, \mathrm{Mg}^{+}$or $\mathrm{H}^{+}$present in the surrounding solution. This maintains the electro-neutrality of sediments. These cations cannot enter into the crystal structure, owing to their size. As described previously, this exchange is made in a diffuse layer where ions are exposed to surface attraction and to diffusion to the inside of the liquid where ion concentration becomes inferior. Like in the case of non-charged porous materials, there is an electrical double layer at the mineral surface comprised of a fixed layer called the Stern layer and of a diffuse layer. The number of cations able to be exchanged per mass unit of the sediment matrix is the Cation Exchange Capacity (CEC). The CEC is expressed in milli-equivalents per $100 \mathrm{~g}(\mathrm{meq} / 100 \mathrm{~g})$ or in meq cm $\mathrm{cm}^{-3}$ if the volume of pores is considered. 'meq' is the ratio of the molecular weight by its valence. The CEC can also be expressed in $\mathrm{C} \mathrm{kg}^{-3}$. The components of shales, illite, kaolinite, smectite and chlorite have differing CEC and densities.

From equations (5) and (7), Revil [24] has also defined a formula taking the CEC of clayed materials into account:

$$
\sigma=\frac{1}{F F}\left[S_{w}^{n} \sigma_{w}+S_{S}^{p} \frac{(F F-1)}{F F \Phi} \beta_{+} \rho_{S}\left(1-f_{m}\right) C E C\right]
$$

where the exponent $p$ can be replaced by $n-1$ in a good first approximation, $\beta_{+}$is the mobility of counterions (counterions compensate the negative charges of the mineral surface), $\rho_{s}$ the density of grains and $\left(1-f_{m}\right)$ the fraction of counterions in the diffuse layer. The expression $\beta_{+} \rho_{s}\left(1-f_{m}\right) C E C$ is equivalent to a surface conductivity.

\section{Effect of SPM on Seawater Conductivity Measurements}

Sediments have higher densities than seawater but they can be put into suspension thanks to convection currents. In order to study the effect of different concentrations of SPM on seawater conductivity, an experimental assembly has been built. It is composed of a cylindrical stainless steel container, an SBE 47 from Sea-Bird Electronics Company and a stirring propeller. The container is filled with a volume $V_{W}=2$ liter of seawater, and immersed in a calibration bath (Figure 1). The temperature of this bath can be stabilized to better than $1 \mathrm{mK}$ (peak to peak) during measurements.

The SBE 47 is an instrument used on mooring lines or mooring cages. Its conductivity cell is common to the other Sea-Bird instruments which are widely used in oceanography. This SBE 47 has been calibrated previously and the measured temperature and conductivity data are corrected beforehand to calculate the seawater salinity using the PSS-78 formulas. The conductivity sensor of the SBE 47 has a resolution of $1 \times 10^{-5} \mathrm{~S} \mathrm{~m}^{-1}$ and a typical stability of $3 \times 10^{-4} \mathrm{~S} \mathrm{~m}^{-1} \mathrm{month}^{-1}$. For this experiment, seawater is pumped through the cell continuously. In order to avoid evaporation, the temperature of the bath is fixed to $10{ }^{\circ} \mathrm{C}$. Thereafter, measurements are realized at a constant salinity. In the cylindrical container, the temperature increases when the sand is added, particularly for important quantities. To avoid temperature errors during conductivity comparisons, measurements are made when the temperature $t$ of the mixture is close to the initial one's $t_{0}$, and measured conductivities $\sigma_{M}$ are corrected with the relation $d \sigma_{M} / d t \mathrm{x}(t$ $t_{0}$ ). It is then possible to observe to the resolution of the SBE $37\left(0.1 \mu \mathrm{S} \mathrm{cm} \mathrm{cm}^{-1}\right)$ the effects of sediments on seawater conductivity, but the sensitivity of the seawater conductivity to temperature being close to $1 \mathrm{mS} \mathrm{cm}^{-1}{ }^{\circ} \mathrm{C}^{-1}$, the accuracy of conductivity comparisons is close to $1 \mu \mathrm{S} \mathrm{cm}^{-1}$.

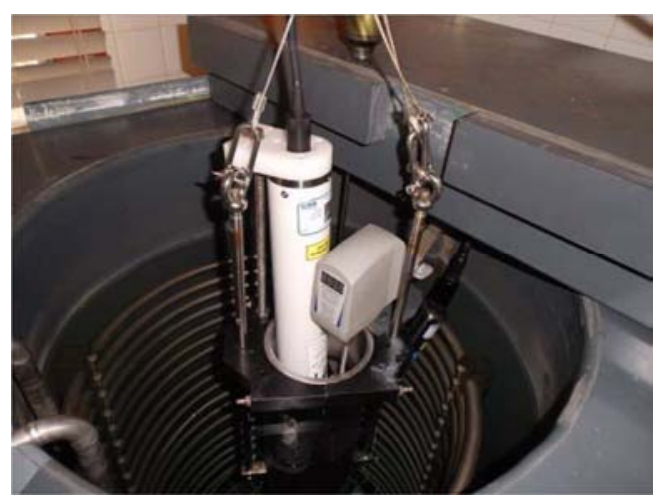

Figure 1. The cylindrical container with a SBE 47 and the stirring propeller in the calibration bath.

Grains of white sand, sufficiently light to be carried along by the wind, were taken from the surface of a beach in the West of France (Plouneour-Trez). They are composed mainly of silica. In order to use the same experimental protocol that $P$. Held et al. [14] used previously, one part (called 'warmed' in the following) was dried in an oven at $55{ }^{\circ} \mathrm{C}$ for a period of at least $24 \mathrm{~h}$. Another part was washed or 'desalted' by 4 successive rinsings in de-ionized water, then dried again. After the drying, the grains of sand showed a high static attraction between them and the glass cupola used to weigh them. During the washings, an increase in the conductivity of the distilled water was observed. The last part (called 'natural') was used without drying or desalting. Samples of sand were weighed with a Mettler AT261 balance and adjusted to $\pm 5 \mathrm{mg}$ to obtain concentrations $C$ from 50 to $5000 \mathrm{mg} \mathrm{l}^{-1}$. These samples were mixed with natural seawaters with practical salinities of around 33.9, 35 and 38. The water at 33.9 comes from the Brest bay and was taken close to the shore. The water at 38 comes from the Mediterranean Sea, and the water at 35 comes from the Atlantic Ocean (Bay of Biscay) and its composition is close to that of standard seawater. For each sand quantity, series of 20 measurements, each lasting $1.5 \mathrm{~min}$, were made. The drift of the seawater salinity was verified before each series of measurements in order to be sure that it was less than $3 \times 10^{-4}$ hour $^{-1}$.

Figures 2, 3 and 4 show the differences observed between the salinity of the seawater alone $\left(S_{0}\right)$ and the average salinity $(S)$ at different concentrations. For concentrations inferior to 
$1.1 \mathrm{~g} \mathrm{l}^{-1}$, it is difficult to establish differences between the different trials, because of the rise of the noise from $0.2 \mathrm{~g} \mathrm{l}^{-1}$ (See figure 5). The amplitude (peak to peak) of the noise $N_{s}$ on the salinity was assessed using the equation $N_{s}=$ $1.176 \times 10^{-5} \times C\left(\mathrm{mg} \mathrm{l}^{-1}\right)$ and on the conductivity using $N_{\sigma}=$ $1.024 \times 10^{-5} \times C\left(\mathrm{mg}^{-1}\right)$. These equations were used to calculate the amplitude of the error bars on the graphs to one standard deviation. They are dependent, so that the average salinity and conductivity deviations, on the rotation speed of the propeller. This speed was chosen in order to obtain the maximal deviation, which also corresponds to the maximal noise. Figure 6 shows the ratio of the standard deviation of measurements series for a concentration of $500 \mathrm{mg} \mathrm{l}^{-1}$ for different rotation speeds of the propeller from 0 to 1200 tr $\min ^{-1}$, to the standard deviation at the null speed. It also shows the ratio of the average deviations of measurement series to the deviation at the null speed. The ratios are maximum at $900 \mathrm{tr}^{\mathrm{min}}{ }^{-1}$ showing that, for this experiment, at this speed, a maximum of sand is in suspension and is pumped in the conductivity cell.

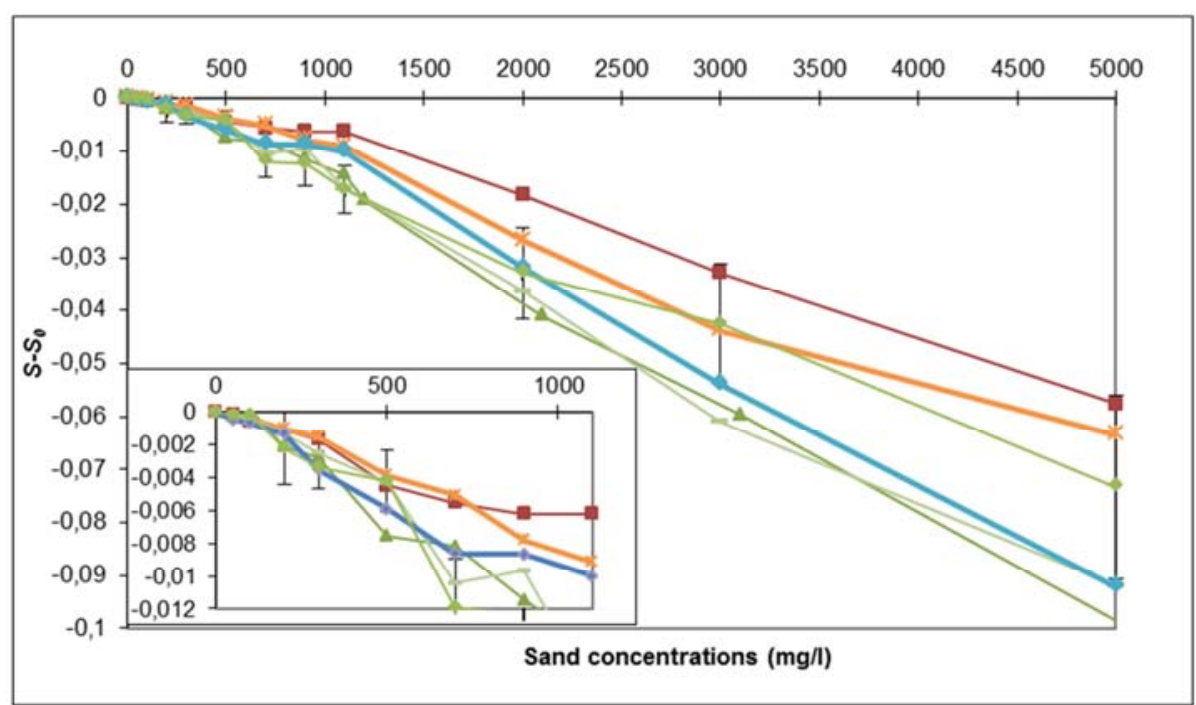

Figure 2. Average salinity differences measured on white sand for $S=33.9$ and $S=35$. Red squares, desalted sand in $S=33.9$ seawater. Orange cross, desalted sand in $S=35$ seawater. Green thin diamonds, first series with natural sand and thick blue diamonds warmed sand in $S=35$ seawater. Green triangles and green dash, second and third series with natural sand in $S=35$ seawater.

Beyond $1100 \mathrm{mg} \mathrm{l}^{-1}$, tendencies are more visible. The seawater at 33.9 from the Brest bay shows a less important decrease in salinity compared to the other experiments made with pure Atlantic seawater at $S$ close to 35 . The more important decreases are obtained during two series performed with natural sand and $S$ close to 35 , but another one conducted under the same conditions shows a slowing decrease beyond $2000 \mathrm{mg} \mathrm{l}^{-1}$. The one standard deviation of the noise can't explain this difference and the change of slope. It could be attributed to a partial filling in of the cell. 'Desalted' and warmed sand samples show less important deviations than the natural samples and the decrease is more linear with 'natural' sand.

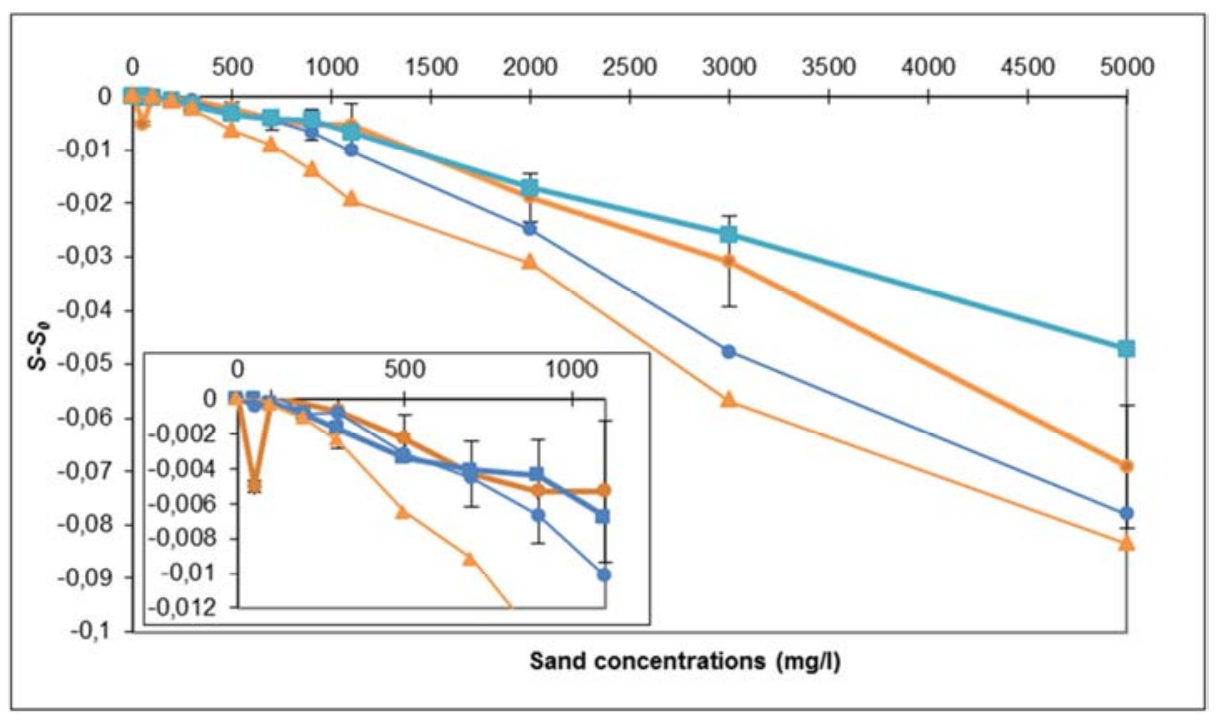

Figure 3. Average salinity differences measured on white sand for $S=38$. Thick blue squares, warmed sand. Orange circles, 'desalted' sand. Blue circles and orange triangles, series one and two with natural sand. 
Figure 3 shows the results obtained with Mediterranean seawater. The less important deviations obtained with 'desalted' and warmed sand are more visible.

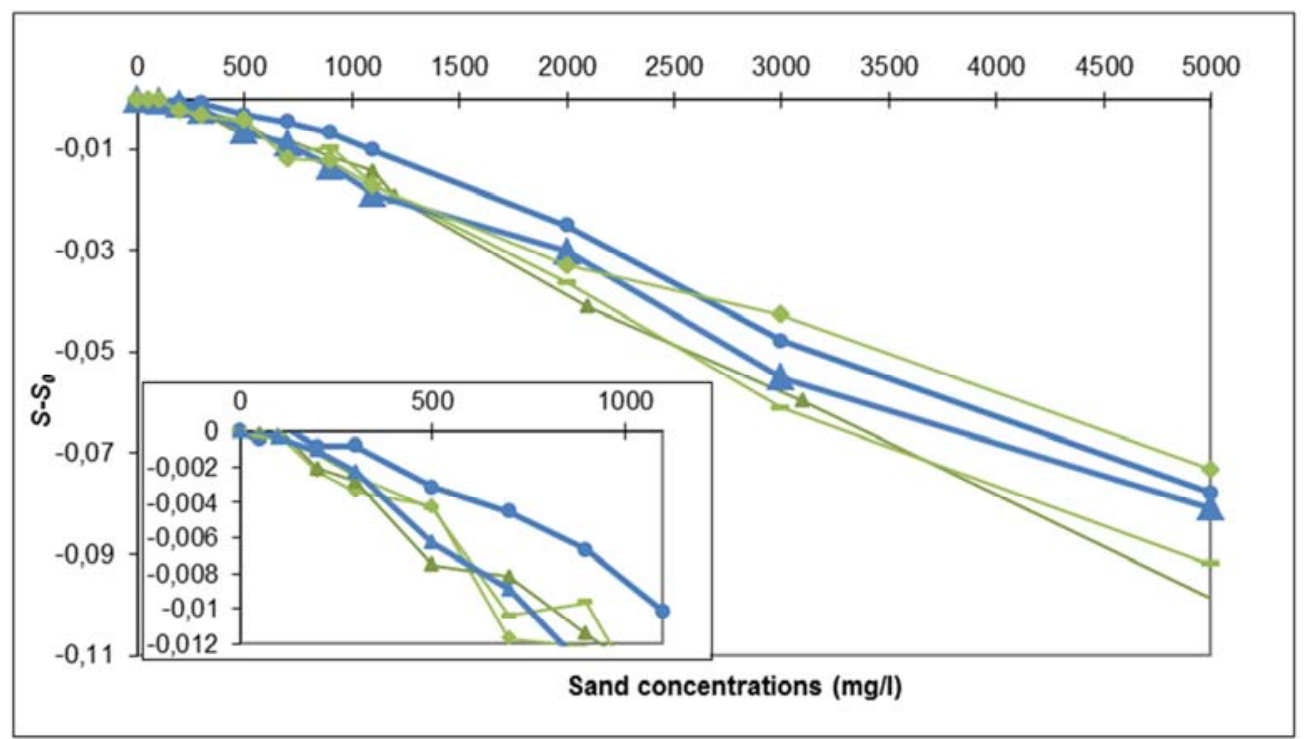

Figure 4. Average salinity differences measured on 'natural' white sand for $S=35$ and $S=38$. Blue circles and triangles, $S=38$. Green diamonds, dash and triangles, $S=35$.

Figure 4, shows series with 'natural' sand for $S=35$ and $S$ $=38$. The effect of sand on seawater conductivity is slightly less important at higher salinities (for the waters at 38 and 35). According to Revil et al. [25], the $\zeta$ potential, which represents the electrical potential at the mineral/water interface, decreases with increasing salinity (but it increases with temperature and $\mathrm{pH}$ ). This explanation is not verified on figure $\mathrm{n}^{\circ} 2$ for $S_{P}=33.9$, probably because this water has a composition or a $\mathrm{pH}$ different from the standard one's and the sand samples have been 'desalted'. According to these measurements, for $S_{P}=35$, the salinity error starts to be superior to 0.002 from $250 \mathrm{mg} \mathrm{l}^{-1}$ and is close to 0.1 at 5000 $\mathrm{mg} \mathrm{l}^{-1} .0 .002$ is the uncertainty expected on practical salinity measurements in open oceans, and it will be considered as a threshold in this document.

At the end of the measurement series, the stirring propeller is stopped and other measurements are made to know the evolution of the salinity as the sand deposits on the bottom of the container. The salinity retrieves its initial value with 0.003 to 0.005 units more, with the 'natural' and the 'desalted' sand. This increase can't be attributed to evaporation because other measurements have been made with the stirring propeller operating for a duration of several hours, showing that evaporation is negligible. The only possible explanations are that the circulation of the sand through the cell or that the mixing of sand in the seawater slightly modify the ionic activity of the water.

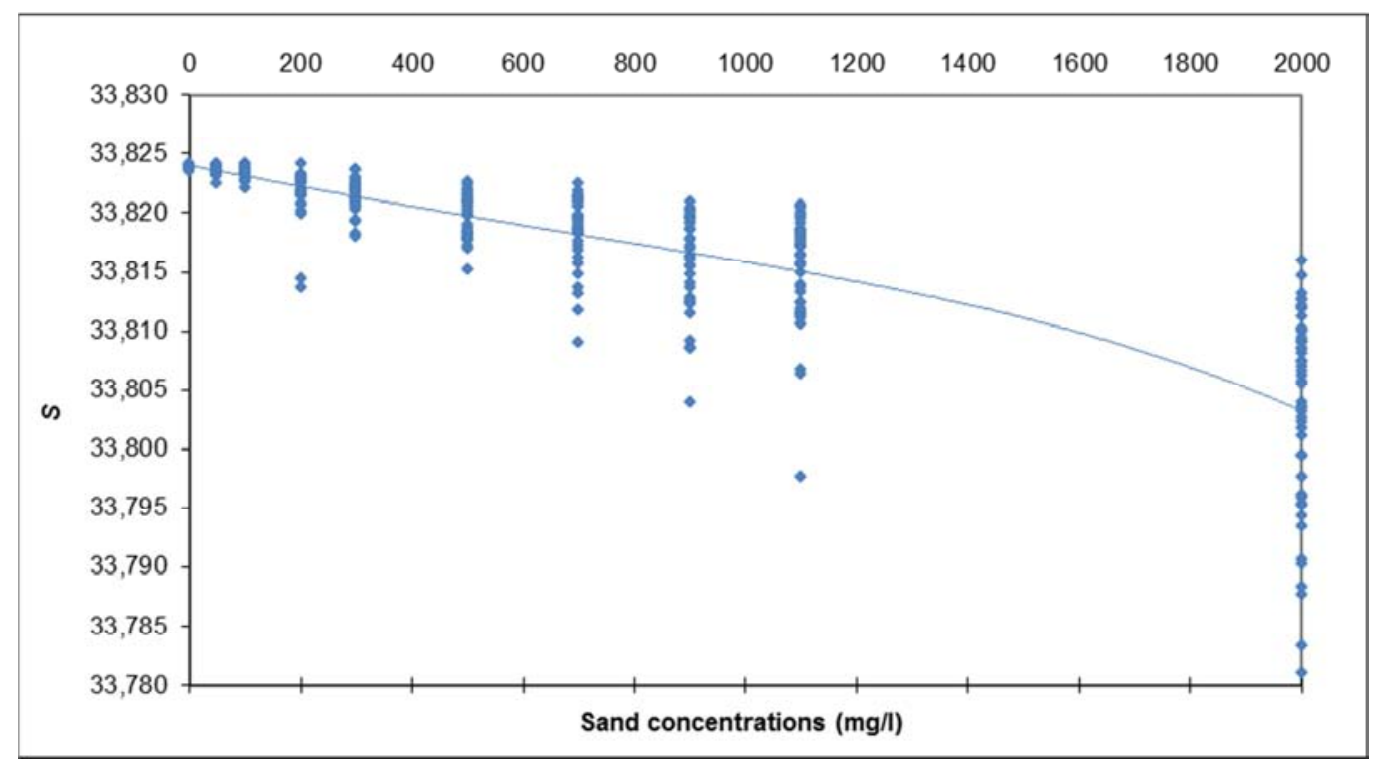

Figure 5. Noize on the practical salinity of a seawater measured with an SBE 37, as the (natural) sand concentration increases. 


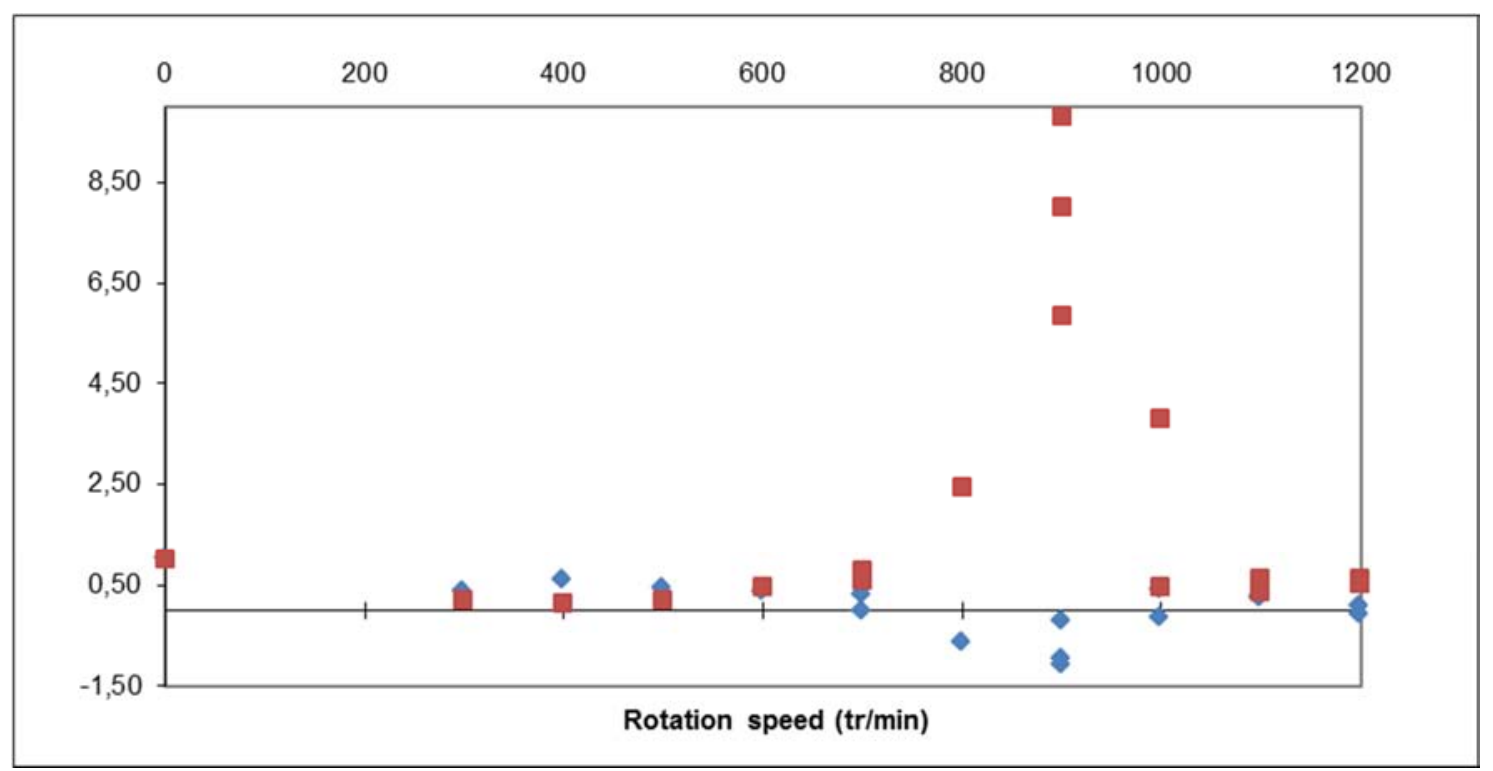

Figure 6. Red squares, ratio of the standard deviation of measurements series for a concentration of $500 \mathrm{mg} l^{-1}$ for different rotation speeds of the propeller from 0 to 1200 tr.min $^{-1}$, to the standard deviation at the null speed. Blue diamond, ratio of the average deviations of measurement series to the deviation at the null speed. The optimal speed is 900 tr $\mathrm{min}^{-1}$.

The same experiment was conducted using mud taken from two different estuaries of the West of France (Abers Benoit, called A, and Le Faou bay, called F) and seawater salinities close to 34 (water from Brest bay). Figure 7 shows the results. These are almost equivalent to the former results, but as the composition of these muds is not known, they cannot be generalized. A change of slope is also visible beyond $1000 \mathrm{mg} \mathrm{l}^{-1}$. Contrary to the results obtained with the pure sand, the desalted mud $\mathrm{A}$ and $\mathrm{F}$ shows important conductivity decreases. The dried grains of mud showed a high static repulsion in the glass cupel during the weighing. That could perhaps explain this change of response.

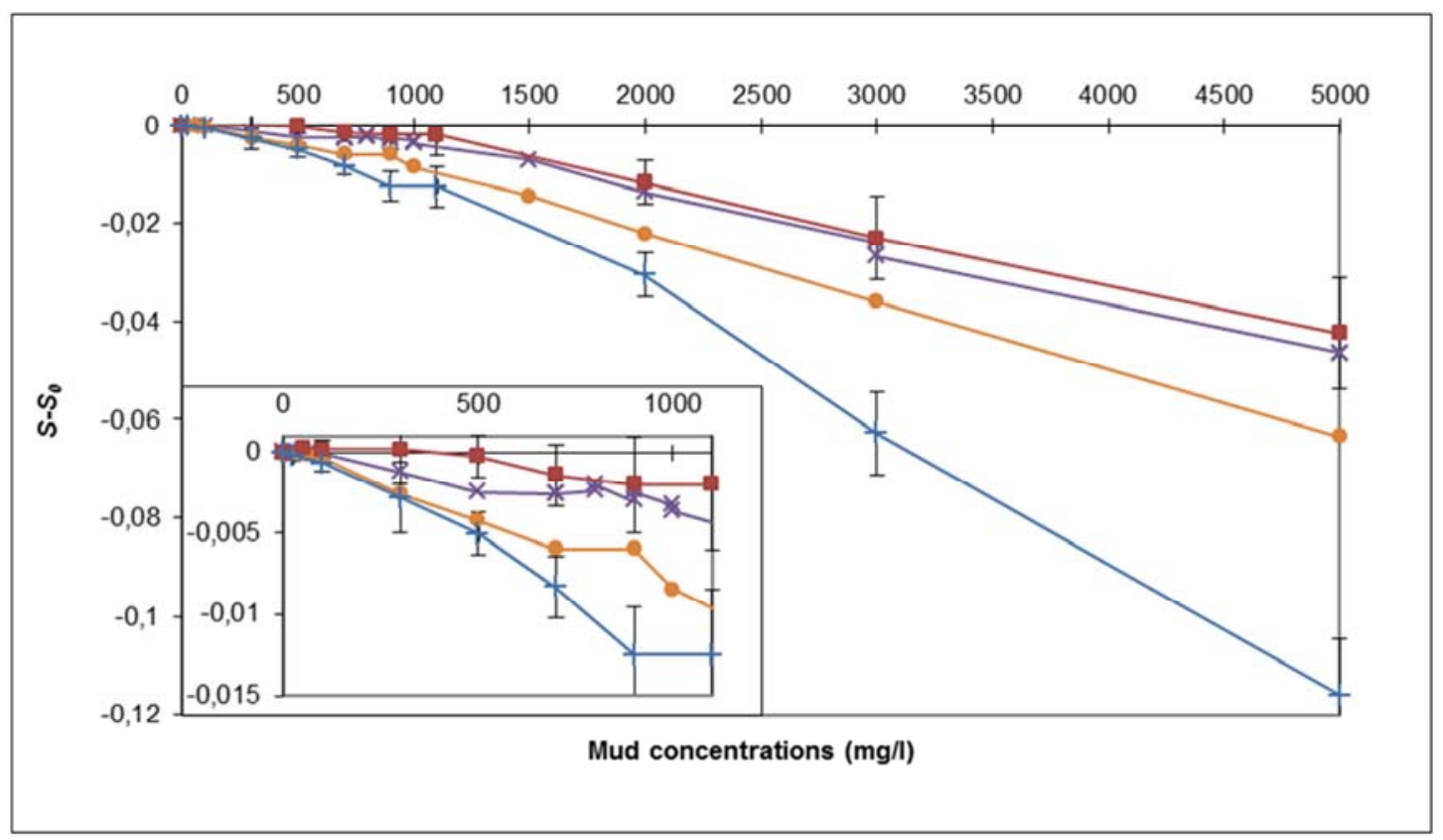

Figure 7. Salinity differences measured on two different muds and a seawater salinity close to 34. Red square, natural mud F, blue cross, natural mud A, orange circle, desalted mud A, blue plus, desalted mud F. The error bars represent the standard deviation of the noise.

\section{Explanation of Effects on Conductivity Measurements}

P. Held et al. [14] have described a 'blinding effect' which occurs when the cross section of a conductivity cell is reduced by sediments. They have tried to demonstrate that this effect is independent on the geometry of the cell and that it depends partially on the conductivity of the sediments, but they didn't try to fit their relation to the observed deviations. They write that, at a given temperature $\left(25^{\circ} \mathrm{C}\right) \sigma_{M}=\sigma_{r e f}$ $V_{W, \text { susp }} / V_{0}$ where $V_{W, \text { susp }}$ is the water volume in suspension, 
$\sigma_{\text {ref }}$ the conductivity and $V_{0}$ the volume of a reference solution. In our case, $\sigma_{r e f}=\sigma_{W}$ and $V_{W, \text { susp }}=\left(V_{W}-V_{s}\right)$ where $V_{S}$ is the added volume of sand. That gives $\sigma_{M}=\sigma_{W}(1-$ $\left.V_{s} / V_{W}\right)$. This relation applied to our experiments shows relative errors for 'natural' sand between 0.04 and 1.62 for $S_{p}$ $=35$ and between 0.062 and 2.00 for $S_{p}=38$. Moreover, the changes of slope and the differences observed between the 'natural' and the 'desalted' sand cannot be explained.

In order to take these remarks into account, we replaced $V_{W}$ by $V_{C}$ the volume of the conductivity cell. The measured resistance $R_{M}$ of a Sea-Bird conductivity cell is:

$$
R_{M}=\frac{1}{\sigma_{M}} \frac{l^{2}}{2 V_{c}}
$$

where $l$ is the length of the cell. If we consider the sum of conductances $\left(R_{M}\right)^{-1}=\left(R_{W}\right)^{-1}+\left(R_{S}\right)^{-1}, R_{W}$ being the resistance of the seawater and $R_{S}$ the resistance of the sediments, we have:

$$
R_{M}=\sigma_{w} 2\left(V_{C}-V_{S C}\right)+\sigma_{S} 2 V_{S C}
$$

where $V_{S C}$ is the volume of sand in the cell. Equating relations (9) and (10), leads us to write the relation:

$$
\sigma_{M}=\sigma_{w}\left(1-\frac{V_{S C}}{V_{C}}\right)+\sigma_{S} \frac{V_{S C}}{V_{C}}
$$

In the case of clean sand, $\sigma_{S}$ can be replaced by the relation (5). For sediments containing clay, the relation (7) could be used instead of the relation (5) and for clayed materials with a CEC, the relation (8) could be used in the same way. The relation (11) therefore becomes:

$$
\sigma_{M}=\sigma_{w}\left[1-\frac{V_{S C}}{V_{C}}\left(1-\frac{S_{n}^{W}}{F F}\right)\right]
$$

It is then necessary to define the value of $V_{S C}$. We can write that the volume of sand $V_{S}$ in the container, multiplied by the efficiency $\varepsilon$ of pumping, is proportional to the volume of sand in the cell $V_{S C}$ :

$$
\frac{V_{T}}{V_{C}}=\varepsilon \frac{V_{S}}{V_{S C}}
$$

where $V_{T}=V_{W}+V_{S}$ is the total volume of the mixture. We have therefore:

$$
V_{S C}=\varepsilon V_{C} \frac{V_{S}}{V_{W}+V_{S}}
$$

We can divide by $V_{S}$ and, as $V_{S}$ can be hardly measured, we can write that $V_{S}=m_{S} / \rho_{S}$ where $m_{s}$ is the added mass of sand and $\rho_{S}$ its density: $\rho_{S}=1.85 \mathrm{~g} \mathrm{~cm}^{-3}$. The relation (14) becomes:

$$
\frac{V_{S C}}{V_{C}}=\frac{\varepsilon}{1+\frac{V_{W}}{V_{S}}}=\frac{\varepsilon}{1+\frac{V_{W} \rho_{S}}{m_{S}}}
$$

The value of $V_{S C} / V_{C}$ can be replaced in the relation (12) to give:

$$
\sigma_{M}=\sigma_{w}\left[1-\frac{\varepsilon}{1+\frac{V_{W}}{V_{S}}}\left(1-\frac{S_{n}^{W}}{F F}\right)\right]
$$

Let's note that in relation (16), if $\varepsilon=0, \sigma_{M}=\sigma_{W}$, which is coherent with observations when the stirring propeller is stopped and that the second term of this relation is the error term of the measured conductivity. This linear relation can explain the decrease in conductivity observed in figure 1 to a sand concentration of between 0 and $900 \pm 400 \mathrm{mg} \mathrm{l}^{-1}$. It is sufficient to explain observations made with concentrations met in open oceans, coastal areas and most of estuaries. Beyond the inflexion point, which for most series is at 1100 $\mathrm{mg}^{-1}$, there is a change of slope and a cumulative effect as the sand doses are multiplied by 2, 3, 4 or 5 in the container. As shown in figures 8 and 9, this cumulative effect can be described by a geometric series of common ratio $q$ :

$$
\sigma_{M_{n}}=\sigma_{w_{n-1}} q^{n}
$$

with $q=\left[1-\frac{\varepsilon}{1+\frac{V_{W} \rho_{S}}{m_{S i p}}}\left(1-\frac{S_{n}^{W}}{F F}\right)\right]$ and $m_{S i p}$ the mass of sand to the inflexion point which corresponds to $\sigma_{M_{1}}$.

These relations have been applied to 'desalted' and 'natural' sand, and results are given in figure 8 for the salinity $S_{p}=35$ and in figure 9 for the salinity $S_{p}=38$. The following values were used: $S_{w}{ }^{n}=1, \varepsilon=1$ and $\rho_{S}=1.85 \mathrm{~g} \mathrm{~cm}^{-3}$. The value of $F F$, which can be considered as an apparent formation factor, was adjusted to fit the results to the measurements. At $S_{p}=35$, for the desalted samples, the inflexion point is at $1100 \mathrm{mg} \mathrm{l}^{-1}$, and the model is in very good agreement with the measurements up to $2000 \mathrm{mg} \mathrm{l}^{-1}$. Beyond this value, a deviation appears, probably because of the efficiency of the pumping for important sand concentrations. The same effect is visible for the first series with 'natural' sand, but for the second series, the model fit the measurements very well up to $5000 \mathrm{mg} \mathrm{l}^{-1}$. According to the relation (16), the conductivity error starts to be superior to $0.001 \mathrm{mS} \mathrm{cm}^{-1}$ beyond $100 \mathrm{mg} \mathrm{l}^{-1}$ and it is superior to $0.002 \mathrm{mS} \mathrm{cm}^{-1}$ beyond $200 \mathrm{mg} \mathrm{l}^{-1}$ for natural sand. 


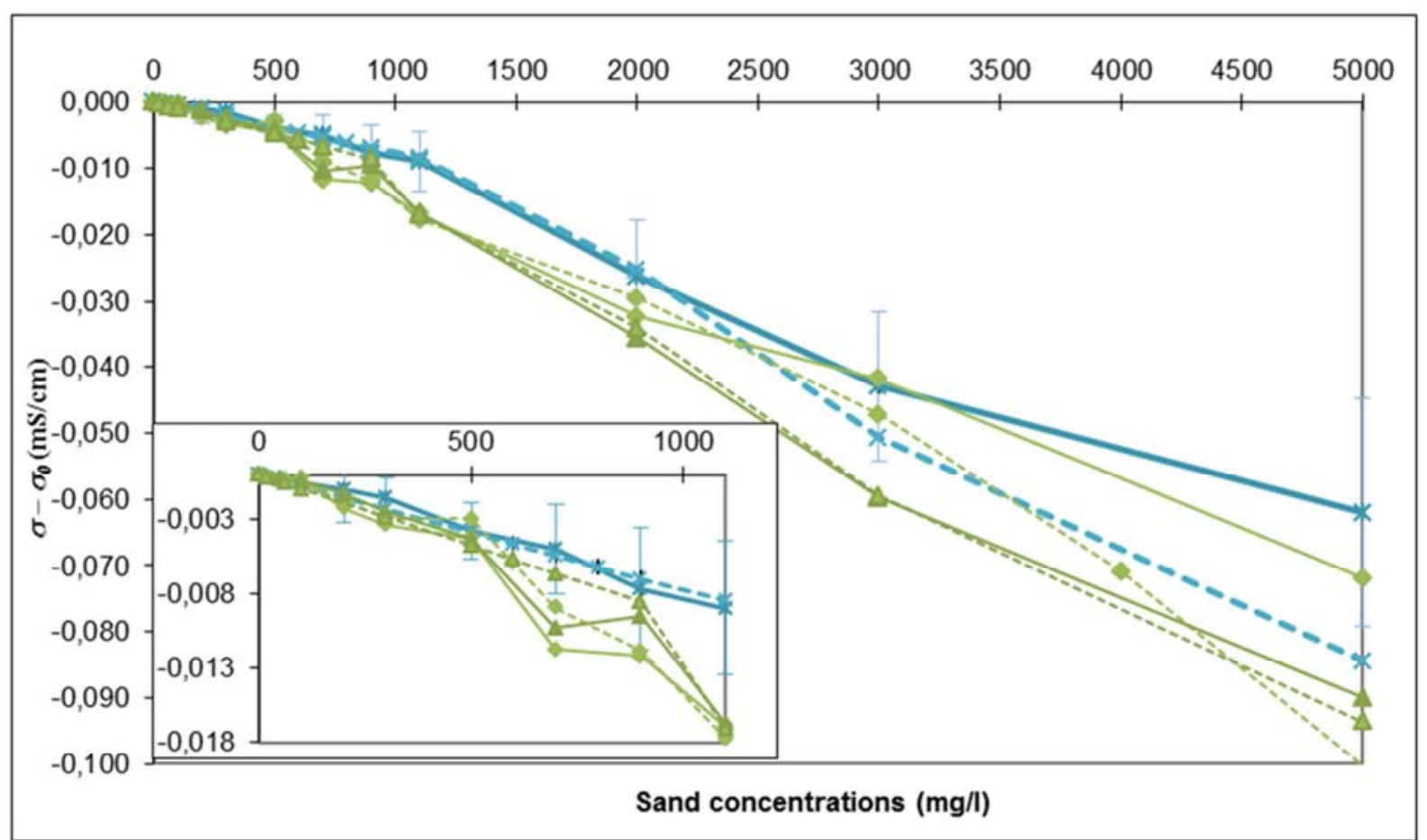

Figure 8. Conductivity differences measured (full lines) and obtained with equations (16) and (17) (Dashed lines) for the salinity $S_{P}=35$. Blue cross, 'desalted'sand, green diamonds and triangles, series 1 and 2 with 'natural'sand.

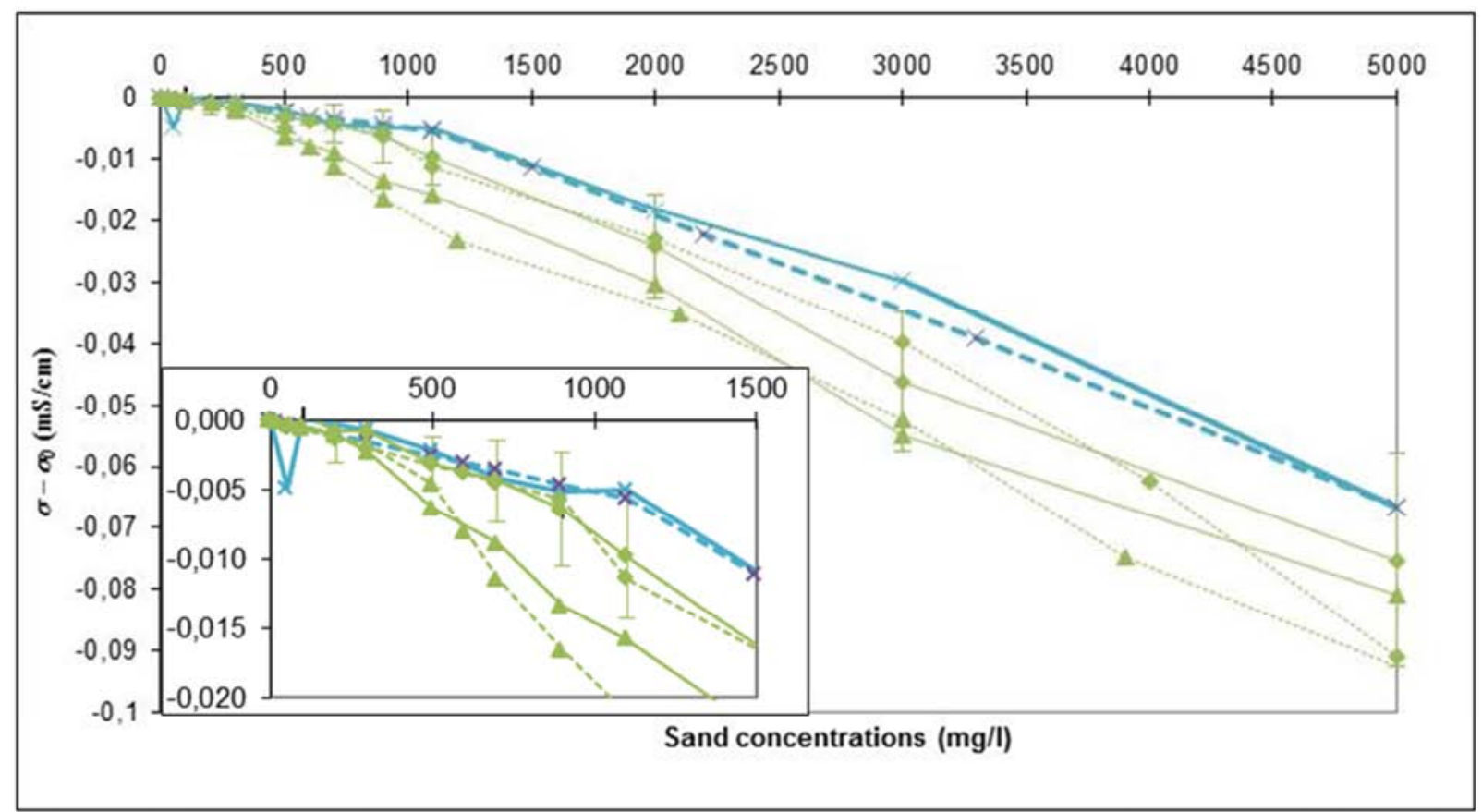

Figure 9. Conductivity differences measured (full lines) and obtained with equations (16) and (17) (Dashed lines) for the salinity $S_{P}=38$. Blue cross, 'desalted'sand, green diamonds and triangles, series 1 and 2 with 'natural'sand.

With $S_{p}=38$ (Figure 9), for the desalted samples, the inflexion point is also at $1100 \mathrm{mg} \mathrm{l}^{-1}$, and the model is in very good agreement with the measurements up to $5000 \mathrm{mg} \mathrm{l}^{-1}$. For the first series with 'natural' sand, it gives a very good result up to $2000 \mathrm{mg} \mathrm{l}^{-1}$. Beyond this value, deviations are visible, but they are inferior to the standard deviation. This result was obtained with an inflexion point at $900 \mathrm{mg} \mathrm{l}^{-1}$. For an unknown reason, the inflexion point is more difficult to determine on the second series with 'natural' sand. Therefore, equations (16) and (17) are more difficult to apply. It was supposed to be at $300 \mathrm{mg} \mathrm{l}^{-1}$, but the fitting is not as good as with the previous series. According to the relation (16), with $S_{p}=38$, the conductivity error starts to be superior to 0.001 $\mathrm{mS} \mathrm{cm}{ }^{-1}$ beyond $160 \mathrm{mg} \mathrm{l}^{-1}$ and it is superior to $0.002 \mathrm{mS} \mathrm{cm}^{-}$ ${ }^{1}$ beyond $350 \mathrm{mg} \mathrm{l}^{-1}$ for natural sand. 
Table 1. Values of the formation factor FF used to obtain the results of figures 8 and 9 , and the corresponding porosities $\phi$.

\begin{tabular}{llll}
\hline Sand & $\boldsymbol{S}_{\boldsymbol{p}}$ & $\mathbf{F F}$ & $\boldsymbol{\phi}$ \\
\hline Desalted & 35.10 & 1.59 & 0.73 \\
Natural & 35.09 & 1.40 & 0.80 \\
Natural & 35.13 & 1.84 & 0.67 \\
Desalted & 37.97 & 1.30 & 0.84 \\
Natural & 37.87 & 1.40 & 0.80 \\
Natural & 37.96 & 1.35 & 0.82 \\
\hline
\end{tabular}

Table 1 shows the different values of FF used to calculate the fitting curves of figures 8 and 9 . They correspond (with one exception) with the values obtained experimentaly by Jackson et al. in 1978 [26], on eight natural marine sands. They used a sand-settling cell with a large sediment chamber above which there was a graduated cylinder full of water and acting as an accurate volume measuring device. The chamber was equiped with electrodes used as a four-electrode method. With this apparatus, they found FF values between 1.39 and 1.58. That confirms the validity of equations (16) and (17).

During the measurements, the humidity of the room was measured in order to determine its influence on the slopes of the curves, but no correlation was found between the variations of FF and the humidity of the air, which could have changed the $\zeta$ potential of the sand before its mixing with the seawater.

\section{Effect of SPM on Seawater Density Measurements}

Grains of sand are not easy to keep in suspension and it is hardly difficult to take a sample from a solution in order to measure its density with a vibrating tube meter like an Anton Paar DMA 5000. To show the effect of SPM on density measurements, we used white kaolin powder. Kaolin particles are not soluble in water and they can be easily kept in suspension. Among the different components of shale, kaolinite has the lower CEC (between 3 - 15 meq/100 g). It is a non-expanding silicate clay composed of a superposition of tetrahedral sheets containing $\mathrm{Si}$ and $\mathrm{O}$ atoms and of octahedral sheets containing $\mathrm{Al}-\mathrm{OH}$ bounds. Kaolin powder particle sizes range between 0.1 and $80 \mu \mathrm{m}$ according to Comparon [27]. This range of sizes is similar, for example, to aerosol particles which can be collected in the North Atlantic Ocean, as collected in 2003 by Buck et al. [28]. It is also similar to the range of sizes found in the Mediterranean Sea by Bressac et al. in 2011 [29] after Saharan dust depositions. These depositions can occur over large areas.

When kaolin powder is mixed with seawater with a salinity of 33.9, the conductivity of the solution decreases strongly, following a slope like desalted mud A in figure 7. Its value is: $d \sigma / d C=-3.4 \times 10^{-5} \mathrm{mS} \mathrm{cm}^{-1} / \mathrm{mg} \mathrm{l}^{-1}$ or $d S / d C=$ $3.15 \times 10^{-5} \mathrm{~g} \mathrm{~kg}^{-1} / \mathrm{mg} \mathrm{l}^{-1}$. Inversely, the densities measured with a DMA $5000 \mathrm{M}$ follow a positive slope $d \rho / d C=5.8810^{-4} \mathrm{~kg}$ $\mathrm{m}^{-3} / \mathrm{mg}^{-1}$. This slope can be accurately retrieved by calculating the density $\rho_{S}$ of the solution:

$$
\rho_{S}=\frac{\left(m_{W}+m_{K}\right)}{V_{T}}
$$

where $m_{W}$ is the mass of water and $m_{K}$ the mass of kaolinite. Using $\rho_{K}$, the kaolinite density, which is $2.65 \mathrm{~kg} \mathrm{~m}^{-3}$, relation (18) becomes:

$$
\rho_{S}=\frac{1}{V_{T}}\left[\frac{\rho_{W}}{\rho_{K}}\left(V_{T} \rho_{K}-m_{K}\right)+m_{K}\right]
$$

Figure 10 shows the density deviations obtained with measured values of different kaolinite solutions and the same deviations obtained with formula (19). Taking into account the measurement uncertainties, the agreement between the measured values and the calculated values is very good.

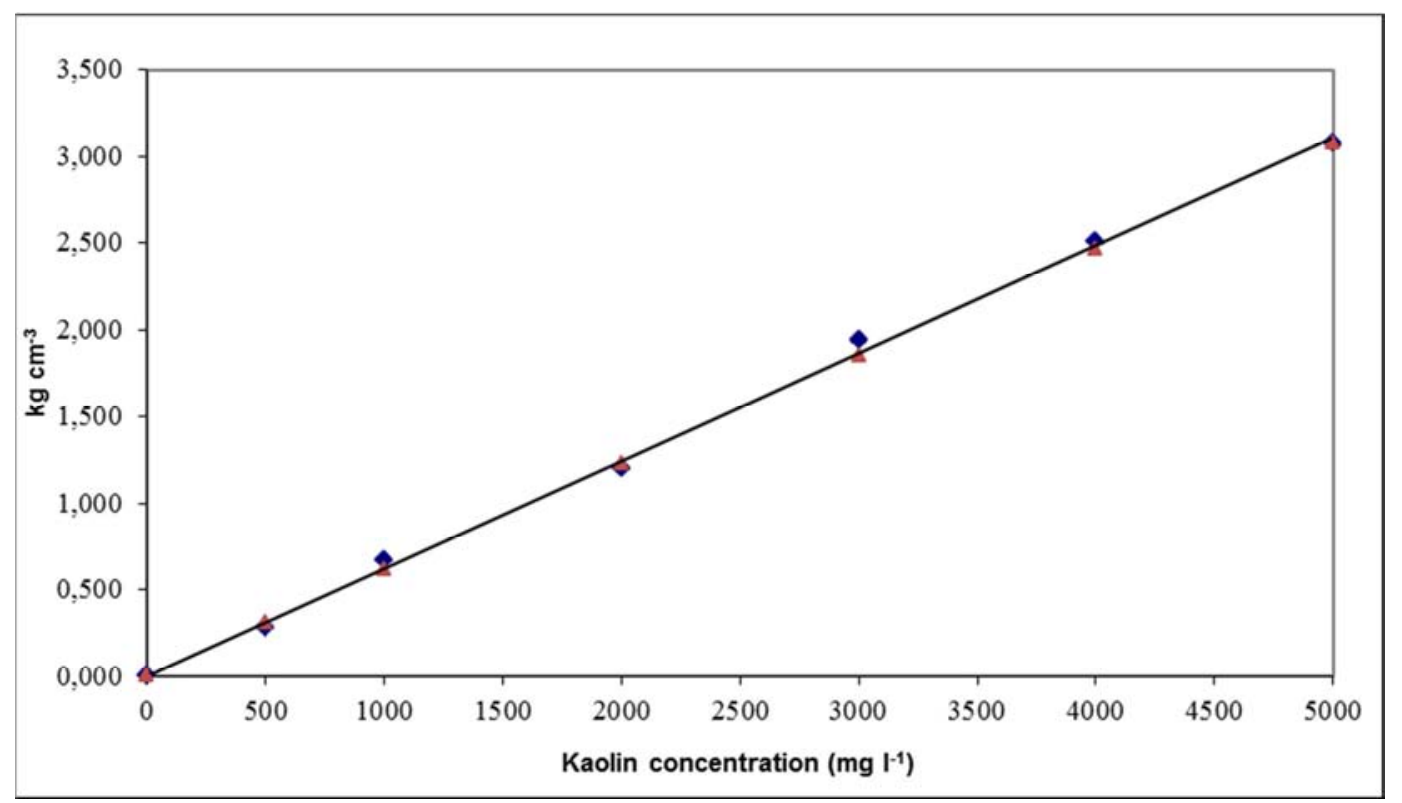

Figure 10. Blue squares, density deviations in $\mathrm{kg} \mathrm{m}^{-3}$ measured with an Anton Paar DMA 5000 M. Brown triangles, density deviations calculated with relation (19). 
This difference of slope suggests that the absolute salinity (of a seawater contaminated with kaolinite or aerosol particles) obtained from practical salinity measurements with relation (1), will show differences with an absolute salinity obtained from density measurements, according to the amount of kaolinite or other particle concentrations. For the sand, the formula (19) shows that the slope will be $4.4610^{-4}$ $\mathrm{kg} \mathrm{m}^{-3} / \mathrm{mg} \mathrm{l}^{-1}$. Beyond $9 \mathrm{mg} \mathrm{l}^{-1}$, the density error will be superior to $0.004 \mathrm{~kg} \mathrm{~m}^{-3}$, which is the uncertainty achievable with a DMA $5000 \mathrm{M}$ and required for ocean absolute salinity measurements. SPM concentrations of $9 \mathrm{mg}^{-1}$ can be found in coastal areas. At $200 \mathrm{mg} \mathrm{l}^{-1}$ and $350 \mathrm{mg} \mathrm{l}^{-1}$, which are the thresholds defined for the sand to keep a practical salinity error inferior to -0.002 , the errors will be 0.089 and $0.156 \mathrm{~kg}$ $\mathrm{m}^{-3}$, respectively. Using relation (4), this corresponds to absolute salinity errors of +0.067 and $+0.117 \mathrm{~g} \mathrm{~kg}^{-1}$.

\section{Conclusion}

The measurements made in the laboratory, in a bath stabilized in temperature, show clearly that sand or mud particles in suspension in seawater modify the conductivity measurements. At first, the amplitude of the measurement noise obtained with the conductivity cell of a SBE 45 is superior to 0.002 in salinity beyond $200 \mathrm{mg} \mathrm{l}^{-1}$. The theories developed by different authors to explain and predict the conductivity of sediments show clearly that, under an electrical field, they interact with the ionic composition of seawater. Second, the measurements realized on natural sand, mud and kaolinite particles show that they attract seawater ions and that this leads to a decrease of the measured conductivity and salinity. This phenomenon is less important when the sand has been previously washed in distilled water. That could suggest that the effect of sand, and mud, on seawater conductivity is not the same when grains have been washed by rain, or by the soft water of a river, before being carried by ocean currents.

The relation of P. Held et al. [14], describing a 'blinding effect', has been tested. It shows relative errors between 0.04 and 2.00 and it can't explain the observed change of slope and the differences between 'natural' and 'desalted' sand. In order to account for these observations, a new relation has been developed based on the sum of sediment and seawater conductance. Archie's relation (5) is used to describe the conductivity of the sand, but Revil's relations (7) and (8) could be used in the same way to predict the conductivity of a solution of clayed materials. It also takes into account the ratio of the volume of water to the volume of sand and the efficiency of the pumping. The change of slope observed on the graphs is attributed to a cumulative effect of sand doses beyond an inflexion point and is described by a geometric series. This approach gives good results by using formation factor values close to these ones found by Jackson et al. in 1978 [26] on eight species of natural marine sands, proving its reliability.

More accurately than measurements, this model allows predictions of changes in seawater conductivity for low sediment concentrations encountered in the open ocean, with different salinities, but also for the high concentrations encountered in estuaries, when the noise and the efficiency of pumping disturb the measurements. The errors in the measured conductivities (and practical salinities) caused by the sand in suspension are inferior to $0.001 \mathrm{mS} \mathrm{cm}^{-1}$ (on average), with concentrations usually seen in oceans fields, but they cannot be neglected in some coastal areas and near some seabed areas. Conductivity measurements to a few meters of light sediments deposits stirred by currents can be erroneous and can lead to underestimations of the density, which can disturb numerical models at the interface with the seabed. For density measurements the threshold for keeping errors inferior to $0.004 \mathrm{~kg} \mathrm{~m}^{-3}$ is much lower, $9 \mathrm{mg}$ $\mathrm{I}^{-1}$, and close to the concentrations encountered in the open ocean. With concentrations beyond this threshold, the differences between absolute salinity values determined from practical salinity measurements and from density measurements increase rapidly due to the opposite signs of the error slopes. Thereafter, complementary turbidity (or noise) measurements can be necessary to determine the need for correcting conductivity measurements, before the calculation of a practical salinity. When using a SBE 37 on mooring, the amplitude of the conductivity noise could be used to assess the SPM concentration, as a first approximation, thanks to a simple relation: $N_{\sigma}=1.024 \times 10^{-5}$ x $C\left(\mathrm{mg} \mathrm{l}^{-1}\right)$. As for density measurements, samples must not be filtered in order to account for the effect of particles on the real density of the seawater, the presence of SPM questions about the possibility of retrieving absolute salinity from density measurements and, particularly, the validity of the relation (4) in coastal areas or rivers plumes. It can be remarked in the same way, that the maximum misfit of $0.5 \mathrm{mg} \mathrm{kg}^{-1}$ in salinity attributed to equation (2) can be obtained with a natural sand concentration of $50 \mathrm{mg}$ $1^{-1}$, which corresponds to conditions seen in some coastal areas.

Lastly, the experimental method described in this publication and the relations (16) and (17) can be used to determine and correct the errors in practical salinity measurements made in coastal and estuary areas, if water samples are collected and SPM-filtered to determine their concentrations and density. Moreover, in the scope of the development of other methods like refractive index to assess absolute salinity, these results show the limits to which CTD measurements can be used as references in the future intercomparisons of results.

\section{References}

[1] IOC, SCOR and IAPSO, 2010, 'The international thermodynamic equation of seawater - 2010: Calculation and use of thermodynamic properties', Intergovernmental oceanographic Commission, Manuals Guides $\mathrm{n}^{\circ}$ 56, UNESCO (English), 196 pp. 
[2] Millero J. F., Pierrot D., 2002, 'Speciation of metals in natural seawaters', Chapter in Chemistry of Marine Water and Sediments, 193-220.

[3] Millero F. J., Feistel R., Wright D. G., MacDougall T. J., 2008a, 'The composition of standard seawater and the definition of the reference - composition salinity scale', DeepSea Res. I, 55, 10-72.

[4] Pawlowicz R., Wright D. G., and F. J. Millero, 2011, 'The effects of biogeochemical processes on oceanic conductivity/salinity/density relationships and the characterization of real seawater', Ocean Sci., 7, 363-387.

[5] Wright D. G., Pawlowicz R., McDougall T. J., Feistel R., and Marion G. M., 2011, 'Absolute Salinity, "Density Salinity" and the Reference-Composition Salinity Scale: present and future use in the seawater standard TEOS-10', Ocean Sci., 7, $1-26$.

[6] Millero J. F., 1978, 'The physical chemistry of Baltic Sea waters', Thalass Jugosl., 14, 1-46.

[7] Millero F. J., Waters, J., Woosley R. J., Huang F., Chanson M., $2008 \mathrm{~b}$, 'The effect of composition on the density of Indian Ocean waters', Deep-Sea Res. I, 55, 460-470.

[8] Millero J. F., Huang F., 2009, 'The density of seawater as a function of salinity ( 5 to $70 \mathrm{gkg}^{-1}$ ) and temperature (273.15 to 263.15 K), Ocean Sci., 5, 91-100.

[9] Millero J. F., Huang F., Woosley R. J., Letscher R. T., Hansell D. A., 2011, 'Effect of dissolved organic carbon and alkalinity on the density of Arctic Ocean waters', Aquat. Geochem., 17, 311-326.

[10] Woosley R. J., Huang F., Millero F. J., 2014, 'Estimating absolute salinity $\left(S_{A}\right)$ in the world's oceans using density and composition', Deep-Sea Res. I, 93, 14-20.

[11] MacDougall T. J., Jackett D. R., Millero J. F., Pawlowicz R., Barker P. M., 2012, 'A global algorithm for estimating absolute salinity’, Ocean Sci., 8, 1123-1134.

[12] Pawlowicz R., Feistel R., McDougall T. J., Ridout P., Wolf H., 2016, 'Metrological challenges for measurements of key climatological observables Part 2: oceanic salinity', Metrologia, 53, R12-R25.

[13] Pawlowicz R., 2015, 'The absolute salinity of seawater diluted by river water', Deep-Sea Research I, 101, 71-79.

[14] Held P., Kegler P., Schrottke K., 2014, 'Influence of suspended particulate matter on salinity measurements', Continental Shelf Research 85, 1-8, DOI: 10.1016/j.csr.2014.05.014.

[15] Archie G. E., 1942, 'The electrical resistivity log as an aid in determining some reservoir characteristics', Petroleum Transactions of the AIME 146, 54-62.

[16] Revil A., Glover P. W. J., 1998, 'Nature of surface electrical conductivity in natural sands, sandstone, and clays', Geophys. Res. Let., 25, 5, 691-694.

[17] Revil A., Glover P. W. J., 1997-I, 'Theory of ionic-surface electrical conduction in porous media', Physical Review B, 55, $3,1757-1773$.

[18] Waxman M. H., and Smits L. J. M., 1968, 'Electrical conductivities in oil-bearing shaly sands', Society of Petroleum Engineer Journal, 107-122

[19] Johnson D. L., Plona T. J., Kojima H., 1986, Proceedings of the second international symposium on the physics and chemistry of porous media, in Physics and Chemistry of Porous Media-II (Ridgefield), edited by Banavar J. R., Koplik J. and Winkler K. W., AIP Conf. Proc. N ${ }^{\circ} 154$.

[20] Leroy P., Devau N., Revil A., Bizi M., 2013, 'Influence of surface conductivity on the apparent zeta potential of amorphous silica nanoparticles', http://dx.doi.org/10.1016/j.jcis.2013.08.012.

[21] Leroy P., Revil A., Kemna A., Cosenza P., Ghorbani A., 2008, 'Complex conductivity of water-saturated packs of glass beads', Journal of Colloid and Interface Science, 321, 103117 .

[22] Revil A., Skold M., 2011, 'Salinity dependence of spectral induced polarization in sands and sandstones', Geophys. $J$. Int., 187, 813-824.

[23] Revil A., Linde N., Cerepi A., Jougnot D., Matthäi S., Finsterle S., 2007, 'Electro-kinetic coupling in unsaturated porous media', Journal of Colloid and Interface Science, 313, $1,315-327$.

[24] Revil A., 2013, 'Effective conductivity and permittivity of unsaturated porous materials in the frequency range $1 \mathrm{mHz}-$ 1 GHz', Water Resources Research, 49, 306-327.

[25] Revil A., Pezard P. A., 1999, 'Streaming potential in porous media. 1. Theory of the zeta potential', Journal of geophysical research, 104, B9, 20,021-20,031.

[26] Jackson P. D., Taylor Smith D., Stanford P. N., 1978, 'Resistivity-porosity-particle shape relationships for marine sands', Geophysics, 43, 6, 1250-1268.

[27] Comparon L., 2005, Etude expérimentale des propriétés électriques et diélectriques des matériaux argileux consolidés', Institut de Physique du Globe de Paris and B. R. G. M. theses.

[28] Buck C. S., Landing W. M., Resing J. A., 2010, 'Particle size and aerosol iron solubility: a high-resolution analysis of Atlantic aerosols', Marine Chemistry, 120, 1-4, 14-24.

[29] Bressac M., Guieu C., Doxaran D., Bourrin F., Obolensky G., Grisoni J.-M., 2012, 'A mesocosm experiment coupled with optical measurements to assess the fate and sinking of atmospheric particles in clear oligotrophic waters', Geo-Mar Letter, 32: 153-164. 